EESTI NSV TEADUSTE. AKADEEMIA TOIMETISED. 28, KOIDË

FOOSIKA * MATEMAATIKA. 1979, NR. 4

ИЗВЕСТИЯ АКАДЕМИИ НАУК ЭСТОНСКОП ССР. ТОМ 28 ФИЗИКА * МАТЕМАТИКА. 1979, № 4

удК 533.924

Э. КРИГЕР, Ю. СУББИ

\title{
О ЯВЛЕНИИ ЭМИССИОННОГО ОХЛАЖДЕНИЯ ТЕРМОКАТОДА
}

\author{
E. KRIEGER, J. SUBBI. TERMOKATOODI EMISSIOONJAHUTUSEST \\ E. KRIEGER, J. SUBBI. EMISSION COOLING OF THERMAL CATHODE
}

(Представлена Н. Эпиком)

Поскольку электроды являются наиболее быстро амортизирующими деталями дуговых установок, понимание происходящих на них процессов имеет большое значение для технических приложений плазмотронов. Нами исследовались режимы работы термокатода из лантанированного вольфрама при следующих параметрах плазмотрона постоянного тока: ток - 50-150A, рабочий газ - азот при атмосферном давлении, расход газа - 1 г/сек.

Хорошо известно, что эмитирующая поверхность катода при его интенсивном охлаждении сжимается в неподвижное катодное пятно диаметром 0,6-0,8 мм с температурой выше $4000 \mathrm{~K}$. Однако в ряде наших опытов наблюдалось образование пятна такого же размера с более низкой температурой, а в центре его проявлялась темная область диаметром 0,3-0,5 мм. Далее будем называть ее темным пятном (рисунок).

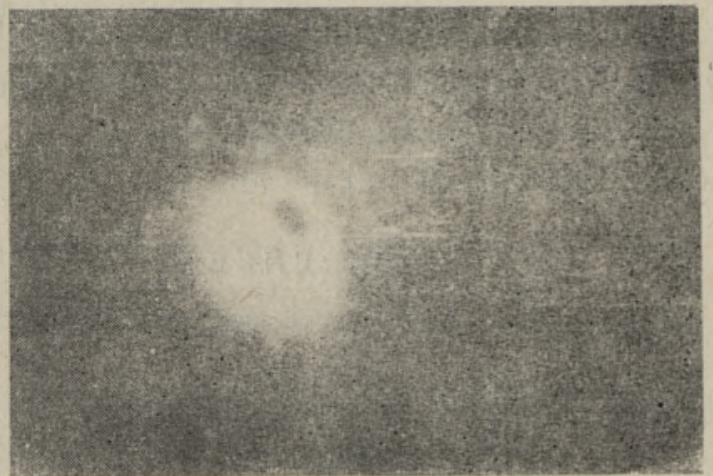

На фоне сплошного спектра сильные линии лантана прослеживались только в излучении темного пятна. Этих линий не было ни в спектре излучения окружающей светлой части, где наблюдались слабые линии вольфрама, ни в спектре струи на расстоянии 0,5 мм от темного пятна. 
Это говорит о том, что лантан не покидает зону нонизации. Он присутствует только в темном пятне, а светлое кольцо состоит из расплавленного вольфрама.

Определение температуры пятна проводилось по спаду интенсивности излучения катода при резком отключении тока $\left[{ }^{1}\right]$. Такой метод позволял исключить вклад излучения плазмы. Средняя по измерениям температура темного пятна составляла $3410 \mathrm{~K}$, а температура окружающей площади - примерно на $300^{\circ}$ выше. Расчет тока термоэмиссии вольфрама показал, что светлое кольцо вокруг темного пятна может дать не более $5 \%$ общего тока, следовательно, основная часть 'тока обеспечивается темным пятном, плотность тока на котором $1,2 \cdot 10^{5} \mathrm{~A} / \mathrm{CM}^{2}$.

Попробуем объяснить такую структуру пятна. С учетом эффекта Шоттки термоэмиссия катода описывается следующими уравнениями $\left[{ }^{2}\right]$ :

$$
\begin{gathered}
j_{e}=A T_{k}^{2} \exp \left(-\varphi / T_{k}\right), \\
\varphi=\varphi_{0}-4,4 E^{1 / 2} / 11609, \\
E=5700 W_{i}^{1 / 4} U_{k}^{1 / 4} j_{i}^{1 / 2}, \\
j_{k}=j_{i}+j_{e},
\end{gathered}
$$

где $j_{k}, j_{\varepsilon}, j_{i}$ - плотности катодного, электронного и ионного токов соответственно, $A / c^{2} ; T_{k}$ - температура катода, K; $\varphi_{0}-$ работа выхода материала катода, $B ; A-$ постоянная Ричардсона, $A / C M^{2} \cdot K^{2} ; U_{k}-$ катодное падение потенциала, $B ; E$ - напряженность электрического поля перед катодом, $B / M ; W_{i}$ - относительная атомная масса иона.

Охарактеризуем поток тепла $Q$ от разряда в катод вольтовым эквивалентом теплового тока $\left[{ }^{2}\right]$ :

$$
Q / j_{k}=\left(j_{i} / j_{k}\right)\left(U_{k}+U_{i}\right)-\varphi,
$$

где $U_{i}$ - потенциал ионизации рабочего вещества. Для оценки величины ионного тока используем неравенство, вытекающее из баланса энергии в зоне ионизации:

$$
j_{e} U_{k} \geqslant j_{i} U_{i}
$$

Поскольку потенциал ионизации лантана много меньше потенциала ионизации азота, можно допустить, что в зоне ионизации перед темным пятном ионизуется только лантан и носителями нонного тока являются только его ионы. Экспериментально доказанный факт, что лантан не покидает зону ионизации, объясняется лишь его полной ионизацией, в связи с чем ионный ток может не достигать максимально разрешенного соотношением (5) значения. Если использовать в (5) знак равенства, приток тепла в катод со стороны разряда увеличивается, но при этом вольтовый эквивалент теплового потока все равно оказывается отрицательным, т. е. имеет место эмиссионное охлаждение катода. Решение системы уравнений (1)-(5) проводилось численно по экспериментальным значениям $T_{k}$ и $j_{h}$. Для лантана использовались следующие величины: $U_{i}=5,61 B ; \quad W_{i}=139 ; A=8,0 A / \mathrm{cm}^{2} \cdot K^{2} ; \quad \varphi_{0}=2,71 B \quad\left[{ }^{3}\right]$. Результат решения приведен в таблице. Ввиду малой плотности тока на окружающей темное пятно поверхности, охлаждения там нет либо оно незначительно. Это и объясняет более низкую температуру в центре пятна, чем по краям. 
Авторы выражают благодарность А. Пурга за ценные критические замечания.

\begin{tabular}{l|c|c|c|c|c|c|c}
$T_{k}, \mathrm{~K}$ & $I, A$ & $d, M M$ & $j_{k}, A / C M^{2}$ & $j_{i}, A / C M^{2}$ & $\Delta \varphi, B$ & $E, B / M$ & $Q / j_{k}, B$ \\
\hline 3410 & 150 & 0,4 & $1,2 \cdot 10^{5}$ & $2,4 \cdot 10^{4}$ & 0,69 & $3,3 \cdot 10^{6}$ & $-0,6$
\end{tabular}

Л И ТЕР А Т У Р А

1. Пу ст ог а ров А. В., В сб.: Экспериментальное исследование плазмотронов, Новосибирск, «Наука», 1977, с. $315-340$.

2. Н е й м а н В., В сб.: Әкспериментальное исследование плазмотронов, Новосибирск, «Наука», 1977, с. 253-292.

3. Фоме н ко В. С., Эмиссионные свойства материалов, Киев, «Наук. думка», 1970.

Институт термофизики и электрофизики

Академии наук Эстонской ССР
Поступила в редакцию 6/VII 1979

EESTI NSV TEADUSTE AKADEEMIA TOIMETISED. 28. KOIDE
FOOSIKA * MATEMAATIKA. 1979, NR. 4

ИЗВЕСТИЯ АКАДЕМИИ НАУК ЭСТОНСКОИ ССР. ТОМ 28

ФИЗИКА * МАТЕМАТИКА. 1979, № 4

удК $518: 517.392$

A. ИЫГИ

\section{О ПРИМЕНЕНИИ НАИЛУЧШИХ КВАДРАТУРНЫХ ФОРМУЛ ПРИ РЕШЕНИИ ИНТЕГРАЛЬНЫХ УРАВНЕНИИ И ВЫЧИСЛЕНИИ СИНГУЛЯРНЫХ ИНТЕГРАЛОВ}

A. JOGI. PARIMATE KVADRATUURVALEMITE KASUTAMISEST INTEGRAALVORRANDITE LAHENDAMISEL JA SINGULAARSETE INTEGRAALIDE ARVUTAMISEL

A. JOGI. ON APPLICATION OF OPTIMAL QUADRATURE FORMULAS FOR SOLUTION OF INTEGRAL EQUATIONS AND EVALUATION OF SINGULAR INTEGRALS

(Представлена А. Хумалом)

1. Рассмотрим решение линейного интегрального уравнения Фредгольма второго рода

$$
x(t)=\int_{0}^{1} h(t, s) x(s) d s+y(t)
$$

при помощи наилучшей на некотором множестве функций квадратурной формулы $\left[{ }^{1}\right]$ вида 